\title{
A Cautionary Note on the Use of LISREL's Automatic Start Values in Confirmatory Factor Analysis Studies
}

\author{
R. L. Brown \\ University of Wisconsin
}

\begin{abstract}
The accuracy of parameter estimates provided by the major computer programs for confirmatory factor analysis studies is questioned. This note demonstrates an inconsistency in parameter estimates across two of the major programs (LISREL and EQS), with the inconsistency attributed to the use of LISREL Vr's automatic start values for the estimation of generalized least squares models.
\end{abstract}

Recently the social science literature has abounded with studies attempting to validate or confirm various factor analytic-based models. These studies have been termed confirmatory factor analysis (CFA) studies; this term simply refers to a test of the validity of a proposed model which is assumed to account for a body of data in terms of relatively few parameters, with the model supposedly based on a priori information (theory or hypothesis).

The confirmatory factor analytic model can be given as

$\mathbf{X}=\mathbf{\Lambda}+\delta$,

where $\mathbf{X}$ is a vector of $k$ observed measures,

$\xi$ is a vector of $m$ underlying or latent factors, such that $m<k$,

$\Lambda$ is a $k \times m$ matrix of factor loadings relating the observed $\mathbf{X}$ to the latent factors $\xi$, and

$\delta$ is a vector of $k$ variables representing random measurement error.

APPLIED PSYCHOLOGICAL MEASUREMENT

Vol. 10, No. 3, September 1986, pp. 239-245

(C) Copyright 1986 Applied Psychological Measurement Inc.

0146-6216/86/030239-07\$1.60
The variance-covariance matrix (hereafter denoted as the covariance matrix) for $\mathrm{X}$ may be defined as $\Sigma=\mathbb{\Lambda} \mathbf{D}^{\prime}+\boldsymbol{\theta}_{\delta}$,

where $\overline{1}$ is the $m \times m$ covariance matrix of $\xi$, and $\Theta_{\delta}$ is the diagonal $k \times k$ covariance matrix of $\widetilde{\delta}$. The structure of a factor analytic model is then defined a priori, and the measurements for parameter estimation on the matrices are submitted, usually in a covariance matrix format. The appropriateness of the factor structure is then tested by attempting to replicate the covariance matrix. Thus, an initial hypothesis is established for test of fit $\left(H_{0}: \mathbb{S}=\hat{\mathbb{A}}\right)$, where $\mathbb{S}$ is the original covariance matrix and is the recovered covariance matrix.

One probable reason for the increase in CFA studies is the availability of computer programs. The major programs available are Jöreskog and Sörbom's $(1976,1978,1982,1984)$ LISREL, Browne and Cudeck's (1983) BENwEE, Schoenberg's (1982) MILS, and most recently Bentler's (1985) EQS. By far the most cited program used for CFA is the Jöreskog and Sörbom (1984) LISREL program. However, the literature fails to provide any comparison of parameter estimates across the various software packages, forcing the user to trust the accuracy of the estimates.

This brief note compares three estimation procedures across two of the more popular programs, LISREL VI Version 6.6 (Jöreskog \& Sörbom, 1984) and EQS Version 2.0 (Bentler, 1985). The estimation procedures used were (1) ordinary least squares (OLS; Equation 3), (2) generalized least 
squares (GLS; Equation 4), and (3) maximum likelihood (ML; Equation 5). Both programs attempt to minimize the following fit functions for the estimates (see Jöreskog, 1983, and Bentler, 1985, for more details):

$$
\begin{aligned}
& \text { OLS }=2^{-1} \operatorname{tr}(\mathbf{S}-\mathbf{\Sigma})^{2} \\
& \mathrm{GLS}=2^{-1} \operatorname{tr}\left[(\mathbf{S}-\mathbf{\Sigma}) \mathbf{S}^{-1}\right]^{2} \\
& \mathrm{ML}=\operatorname{tr}\left(\Sigma^{-1} \mathbf{S}\right)-\log _{\mathrm{e}}\left|\mathbf{\Sigma}^{-1} \mathbf{S}\right|-k
\end{aligned}
$$

where $\mathbf{S}$ is the observed moment matrix (covariance),

$\Sigma$ is the theoretical moment matrix (covariance), and

$k$ is the number of observed variables.

The data used in this comparison were obtained from Long (1983) on Wheaton's (1978) study concerning the psychological disorders of patients over two time periods (1967 and 1971). The variables are (1) psychological disorders in 1967 , (2) psychophysiological disorders in 1967 , (3) psychological disorders in 1971, and (4) psychophysiological disorders in 1971.' The correlations, variances, and covariances are reported in Table 1.

The initial CFA model proposed by Long (1983) was used as the comparison device to obtain parameter estimates from both programs (see Figure 1). The model was not further refined. Parameter estimates, standard errors and tests of significance (where applicable) for OLS, GLS, and

It should be noted that the number of patients reported in Long's (1983) appendix is a misprint and should read 630 patients, not 63 (Long, personal communication, March 6, 1986).
ML procedures from both the LISREL and EQS programs are in Table 2; the estimates obtained by Long (1983) using LISREL V (Jöreskog \& Sörbom, 1982) and MILS (Schoenberg, 1982) are in Table 3. Also indicated are the degrees of freedom, estimated likelihood ratio test (chi-square value), probability estimates, and various indices of fit.

One very interesting finding concerns the estimates given by the LISREL VI GLS procedure. Because these data were previously analyzed by Long (1983) using LISREL $V$ and Schoenberg's (1982) MILS programs, initial parameter estimates are available for comparison, if Long's estimates are correct. Because the EQS program essentially recovered all of Long's parameter estimates (with minor differences, most likely due to rounding errors) and the LISREL VI OLS and ML did the same, it is safe to say that Long's estimates are appropriate. This leaves the problem of why the LISREL. VI GLS procedure did not recover the estimates.

The LISREL VI GLS procedure produced confusing results. The most obvious inconsistency was produced by the likelihood ratio $\left(\mathrm{L}^{2}\right)$, providing a value of .03 with one degree of freedom. This ratio was very different from the ratio reported by Long (1983) and the finding provided by Bentler's EQS. A recalculation of the $\mathrm{L}^{2}$ ratio using Equation 6 indicated a value of 29.58 with one degree of freedom:

$\mathrm{L}_{\mathrm{GLS}}^{2}=[(N-1) / 2] \operatorname{tr}\left[(\mathbf{S}-\hat{\mathbf{Z}}) \mathbf{S}^{-1}\right]^{2}$,

where df $=.5 k(k+1)-t$,

$k$ is the number of observed variables in the analysis, and

$t$ is the number of independent parameters to be estimated.

Table 1

Correlations, Covariances and Variances (14:630) (Correlations in uppers triangle)

\begin{tabular}{ccccc}
\hline & 1 & 2 & 3 & 1 \\
\hline 1 & 2.102 & 0.354 & 0.526 & 0.377 \\
2 & 0.365 & 0.308 & 0.247 & 0.309 \\
3 & 1.053 & 0.189 & 1.904 & 0.549 \\
& 0.275 & 0.086 & 0.381 & 0.253 \\
& & & &
\end{tabular}

Mote. Adagted Erow heaton (1978). 
Figure 1

Model 1: A Model for the Measurement of Psychological Disorders

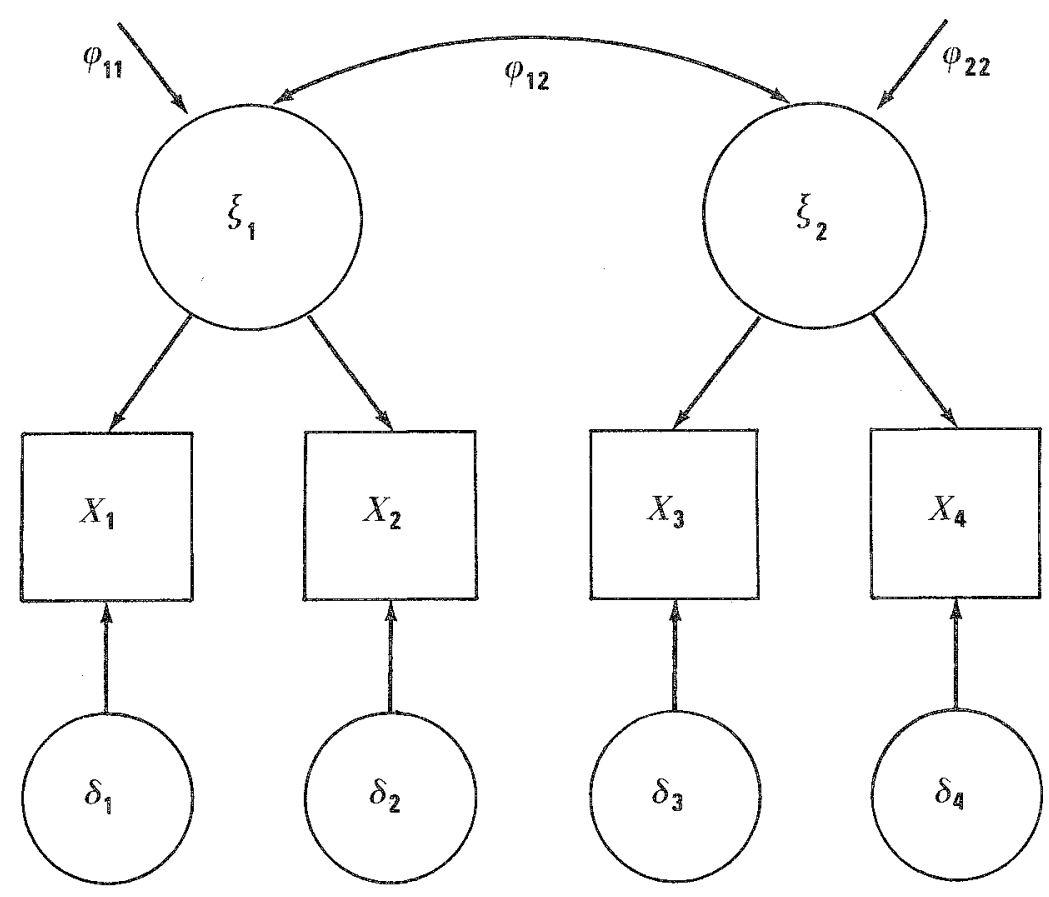

This initial finding indicates a LISREL VI problem in the calculation of $\mathrm{L}^{2}$. Because $\mathrm{L}^{2}$ is contingent upon the parameter estimates, the accuracy of these estimates is also questionable, because the $\mathrm{L}^{2}$ value provided by LISREL VI did not equal the values given by Long (1983) or by using Bentler's (1985) EQS program. Recalculation of Jöreskog and Sörbom's (1984) goodness-of-fit index (GFl) and adjusted goodness-of-fit index (AGFI) also provides evidence of a problem with the estimates, with a GFI of .9836 (versus 1.000) and an AGFI of .8362 (versus 1.000), using Equations 7 and 8 respectively.

$$
\begin{aligned}
& \mathrm{GFI}=1-\frac{\operatorname{tr}(\hat{\mathbf{\Sigma}}-1 \mathbf{S}-\mathbb{I})^{2}}{\operatorname{tr}(\hat{\mathbf{\Sigma}}-1 \mathbf{S})^{2}} . \\
& \mathrm{AGFI}=1-[K(K+1) / 2 d](1-\mathrm{GFI}),
\end{aligned}
$$

where $d$ is the degrees of freedom.
An examination of the GLS estimates provided by LISREL VI (Table 2), along with their standard errors, reveals problems (especially with the $O_{\delta}$ matrix) as compared with the other programs' estimates. Also apparent, though not expected, is striking similarity between the GLS and the OLS estimates.

A second model was also estimated using ML and GLS estimates from both programs. Data were obtained from Kenny (1979, p. 146). The inconsistency in GLS estimates between LISREL VI Version 6.6 and EQS was again detected (results are not reported here).

One possible source of the problem was hypothesized to be the use of automatic start values in obtaining the parameter estimates. To test this hypothesis, data from Long's (1983) initial model were submitted to the LISREL and EQS programs for both ML and GLS estimates, using automatic start 
T요일

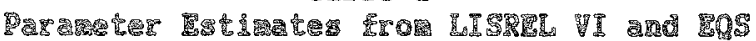

\begin{tabular}{|c|c|c|c|c|c|c|c|}
\hline 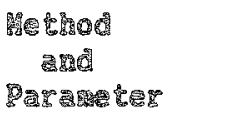 & OLS & GLS & $\hat{\sigma}$ & $c^{6}$ & 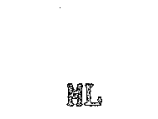 & $\hat{\sigma}$ & 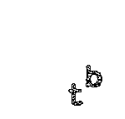 \\
\hline \multicolumn{8}{|c|}{ 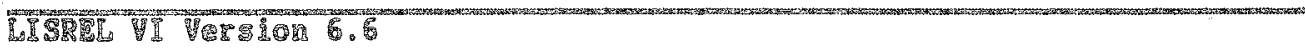 } \\
\hline$\lambda_{I I}$ & 1.000 & 1.6100 & 6. & 0.000 & 1.0.040 & 0.00 & 0.000 \\
\hline$\lambda_{21}^{+1}$ & 0.188 & 0.187 & 0.055 & 2.85 & 0.205 & 0.205 & $.05 \%$ \\
\hline$\lambda_{32}$ & 1.098 & 1.000 & 1. . & 0.00 & 1.607 & 0.000 & 0.000 \\
\hline$\lambda_{42}$ & - .26 & 0.98 & 1.67\% & 3.65 & 0.87 & 0.020 & 11.3.3 \\
\hline$\phi_{11}$ & 1.939 & 1.93 & 9.96 & 急。075 & 1.781 & 0.221 & 8.059 \\
\hline$\phi_{22}$ & 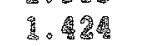 & 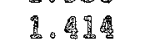 & 1.33 & 管. & 1. 뎡을 & - . 140 & 9.502 \\
\hline$\phi_{12}$ & 1.051 & 1.65 & 0.135 & 29.67 & 1.9. & 0.90 & 12.65 \\
\hline$\theta_{11}$ & 1. 10 & 0.150 & 0.961 & 0.15 & 0.325 & 0.192 & 1.719 \\
\hline$\theta_{22}$ & 1. 23 & 0.250 & 0.28 & 1.6.2. & 0.933 & 0.025 & 15.207 \\
\hline$\theta_{33}$ & . & 0. & 6.62 & 0.792 & 0.927 & 0.110 & 4. \\
\hline$\theta_{44}$ & ט.151 & 0.135 & 1.37 & 10.6 & 0.150 & 0.01 & 13.065 \\
\hline $\operatorname{cog}\left(\xi_{1} \xi_{2}\right)$ & $\rightarrow$ & - & $\rightarrow$ & - & - & - & - \\
\hline 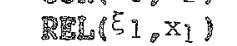 & 0.92 & 0.925 & - & - & 0.84 & - & - \\
\hline 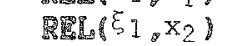 & 0.228 & 0.18 & - & - & 0.283 & - & - \\
\hline R⿴囗十 $\left(\xi 2, x_{3}\right)$ & 1.78 & 9.9 & - & - & 0.739 & - & - \\
\hline 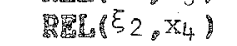 & 9.903 & 的. & - & $\infty$ & 0.69 & - & - \\
\hline QT: & 1. & 1.000 & - & - & 0.985 & - & - \\
\hline 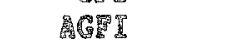 & (7. 998 & 1. & - & - & . & - & - \\
\hline 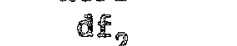 & 1 & 1 & - & - & 1 & - & - \\
\hline 正 & $=$ & 0.030 & - & - & 19.130 & - & - \\
\hline 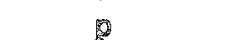 & - & 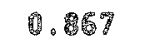 & $\infty$ & $-\infty$ & - & $\infty$ & - \\
\hline \multicolumn{8}{|c|}{ 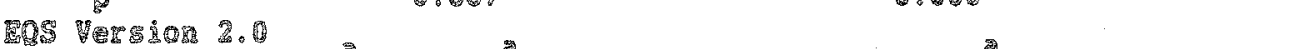 } \\
\hline$\lambda_{11}$ & 1. 10.8. & 1. & . & 0.000 & 1.900 & .009 & 0.000 \\
\hline$\lambda_{21}$ & 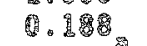 & 0.205 & 4.0.5 & 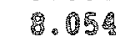 & . 205 & 1.025 & 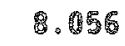 \\
\hline$\lambda_{32}$ & 1.00 & 1. 000 & 0.006 & 1.010 & 1. $0190^{\circ}$ & . .09 & 1.000 \\
\hline$\lambda_{42}$ & 角。息 & .271 & - & 19.391 & 雾, 照 & . & 基.31 \\
\hline$\phi 11$ & 1.938 & 1.79 & . 223 & . & 1.781 & 0.221 & 3.056 \\
\hline$\phi_{22}$ & 1. & 1. & (1) & $9.5 \% 3$ & 1. & 6.198 & 9.49 \\
\hline$\phi 12$ & 1. 15 I & 1. 145 & .090 & 1耳.598 & 1. 145 & 1.000 & 11.65 \\
\hline$\theta_{11}$ & 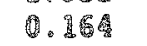 & 1. .9193 & 1930 & 1.53 & 1. 32 & 18 & 1.710 \\
\hline$\theta_{22}$ & 12.33 & 1.2.20 & 0.015 & 5.602 & 6.23 & 0.015 & 15.299 \\
\hline$\theta_{33}$ & 1. 좀 & 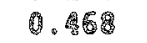 & 1.112 & 臬.21 & 0.97 & 0.110 & 4. 35 \\
\hline$\theta_{44}$. & 0.151 & 0.135 & 0. & 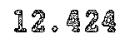 & 0. 150 & 0.011 & 33.18 \\
\hline $\operatorname{Cog}\left(\xi_{1}, \xi_{2}\right)$ & 0.53 & 0.52 & - & - & 9.60 & - & - \\
\hline Xe $\left(\xi_{1}, x_{1}\right)$ & $\infty$ & - & - & - & - & $\infty$ & - \\
\hline 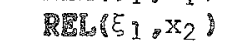 & - & $=$ & - & - & - & - & - \\
\hline 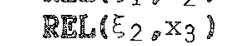 & $-\infty$ & - & - & - & - & - & - \\
\hline $\mathrm{R}_{\mathrm{a}} \mathrm{IL}_{2} \mathrm{x}_{4}$ & - & $=$ & $\infty$ & $=$ & - & $-\infty$ & $\infty$ \\
\hline G & - & - & - & - & - & - & - \\
\hline AGG & - & - & - & - & - & $\Rightarrow$ & - \\
\hline 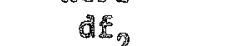 & 1 & 1 & - & - & I & - & - \\
\hline $\mathrm{L}$ & - & 19.295 & - & - & 13.130 & - & - \\
\hline 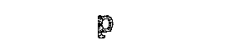 & - & .100 & - & - & 0.000 & - & - \\
\hline
\end{tabular}

Pas

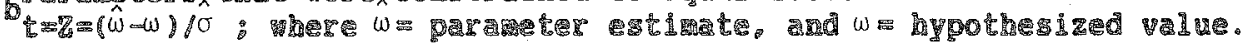


ำ

LISRE

\begin{tabular}{|c|c|c|c|}
\hline 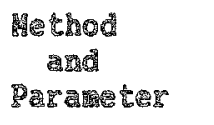 & OLS & GLS & 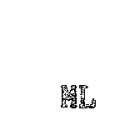 \\
\hline$\lambda_{11}$ & $1.000^{\circ}$ & $1.000^{\circ}$ & 息.9001 \\
\hline$\lambda_{21}$ & 0.18 & 6.205 & 9.205 \\
\hline$\lambda_{32}$ & $1.000^{\circ}$ & 1. $100^{\circ}$ & 1. \\
\hline$\lambda_{42}$ & 0.28 & 0. . 270 & 1.271 \\
\hline$\phi 11$ & 3. 38 & 1.900 & 1.791 \\
\hline$\phi_{22}$ & 1. & 2.431 & 1. \\
\hline$\phi_{12}$ & 1.61 & 1. 106 & 3.0.5 \\
\hline$\theta_{11}$ & 1. 16 & 0.390 & 1. 328 \\
\hline$\theta_{22}$ & 0.35 & 0.520 & 0.233 \\
\hline$\theta_{33}$ & 1. & 0.967 & 0.697 \\
\hline$\theta_{44}$ & 0.156 & 1. 息为 & 4.154 \\
\hline $\operatorname{COR}_{3} \xi_{1}, \xi_{2}$ & 1.63 & 0.65 & 1.60 \\
\hline 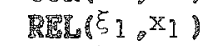 & 6.92 & 0.95 & 0. \\
\hline REL $\left(\xi_{1}, x_{2}\right)$ & . 282 & 9.286 & 0.296 \\
\hline 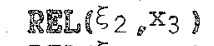 & 1.78 & 0.755 & 0.739 \\
\hline 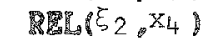 & 0.90\% & 9. & 0.607 \\
\hline QP & - & - & $=$ \\
\hline 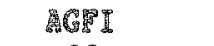 & $\infty$ & $=$ & - \\
\hline 固急 & 1 & 3 & 1 \\
\hline$b_{8}^{2}$ & - & 17.32 & 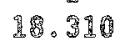 \\
\hline 8 & - & 9.96 & 1.010 \\
\hline
\end{tabular}

values and user-specified start values. Table 4 shows the results. No difference across programs could be detected between the ML estimates using either automatic or user-specified start values, while an inconsistency was discovered between the LISREL VI GLS estimates. It may be concluded that the use of automatic start values provides inappropriate estimates when using the GLS procedure. This has been verified by Jöreskog (personal communication, May 7, 1986). The problem was identified as a programming error in LISREL VI Version 6.6, with intermediate calculations being placed in the $\mathbb{S}^{-1}$ matrix location of the program. This subsequently leads to inaccurate results when the $S^{-1}$ matrix is used to complete the estimates.

This problem may be easily avoided by specifying Ns (not to compute initial estimates and start iteration by the steepest descent from a given start value) on the output line, and then specifying user start values. Use of the two-stage least squares solution as starting values is also suggested for optimal performance in larger models.

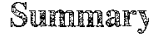

Most university computer centers maintain an array of sofware that will provide parameter estimates in confirmatory factor analysis. Because new statistical techniques make researchers dependent on computer programs, the accuracy of which can rarely be verified independently, it is suggested that replication of parameter estimates using two independent programs may not be inappropriate. 


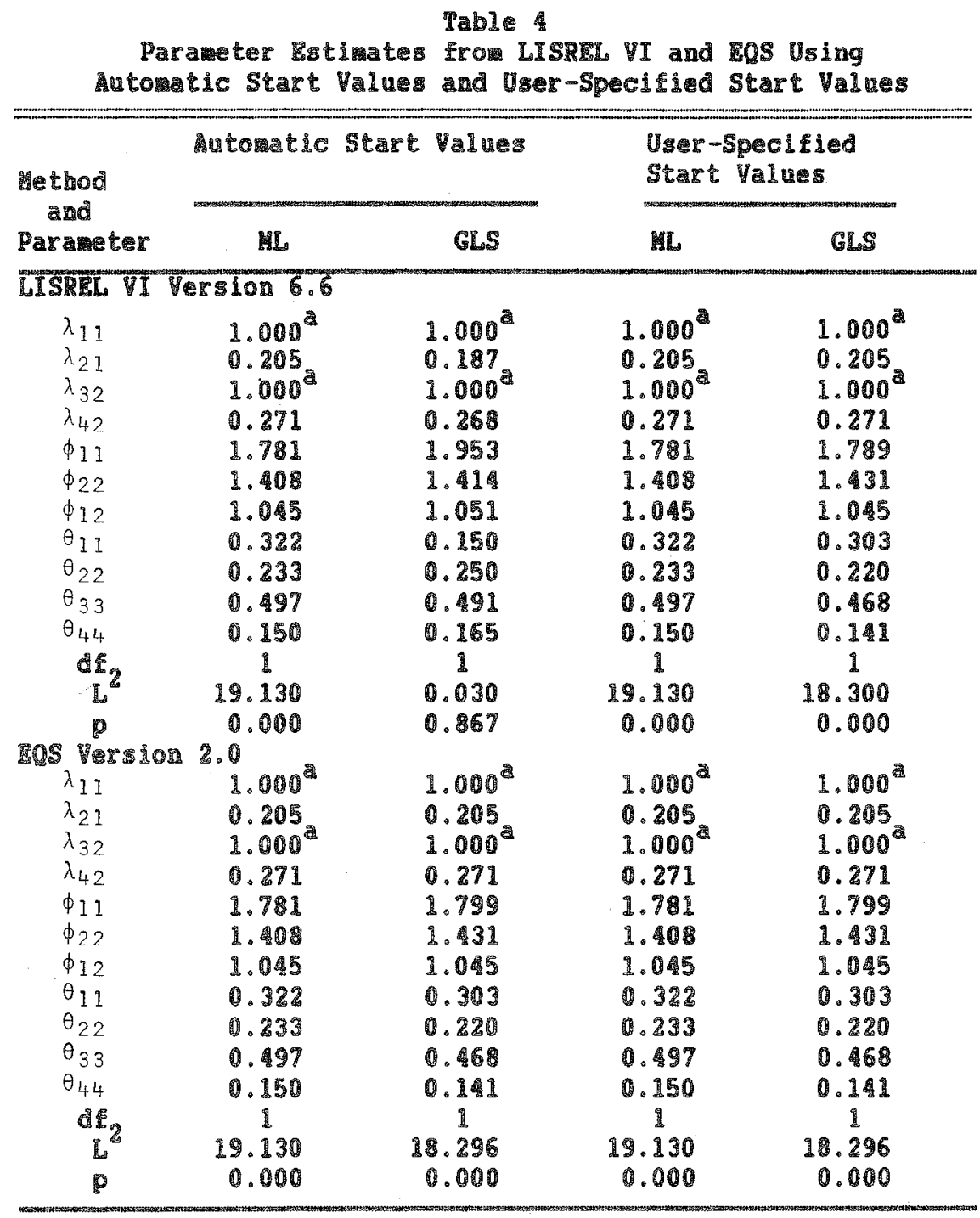

aaramets that

\section{References}

Bentler, P. M. (1985). Theory and implementation of EQS a structural equations program. Los Angeles: BMDP Statistical Software, Inc.

Browne, M. W., \& Cudeck, R. (1983). BENWEE (Version 2): A computer programme for path analysis with latent variables. Pretoria, South Africa: Human Services Research Council.

Jöreskog, K. G. (1983). Structural equation modeling with LISREL: Introduction to LISREL. Uppsala, Sweden: University of Uppsala, Department of Statistics.

Jöreskog, K. G., \& Sörbom, D. (1976). LISREL III: Estimation of linear structural equation systems by maximum likelihood methods [Program manual]. Chicago: National Educational Resources.

Jöreskog, K. G., \& Sörbom, D. (1978). LISREL IV: A general computer program for estimation of a linear structural equation system by maximum likelihood methods. Chicago: International Educational Services. 
Jöreskog, K. G., \& Sörbom, D. (1982). LISREL V: Analysis of linear structural relationships by maximum likelihood and least squares methods. Chicago: International Educational Services.

Jöreskog, K. G., \& Sörbom, D. (1984). LISREL VI: Analysis of linear structural relationships by the method of maximum likelihood. Mooresville IN: Scientific Software, Inc.

Kenny, D. A. (1979). Correlation and causality. New York: Wiley.

Long, J. S. (1983). Confirmatory factor analysis. Beverly Hills CA: Sage Publications.

Schoenberg, $\mathbb{R}$. (1982). MlLS: A computer program to estimate the parameters of multiple indicator linear structural models. Bethesda MD: National Institutes of Health.

Wheaton, B. (1978). The sociogenesis of psychological disorder. American Journal of Sociology, 73, 14691473 .

\section{Acknowledgments}

The author thanks Larry Neuman for first bringing this inconsistency to light, and Karl Jöreskog for his assistance in tracking the problem.

\section{Author's Address}

Send requests for reprints or further information to $R$. $L$. Brown, Schizophrenia Research, School of Social Work, 425 Henry Mall, University of Wisconsin, Madison WI 53706, U.S.A. 